\title{
GERMINAÇÃO E PRODUÇÃO DE MUDAS DE TAMBORIL (Enterolobium contortisiliquum) PARA USO EM RECUPERAÇÃO DE ÁREAS DEGRADADAS
}

Flávio Henrique Miranda Silva - rick.miranda69@ hotmail.com

Faculdades Santo Agostinho

Murilo Antônio Oliveira Ruas - muriloantonio99@yahoo.com

Faculdades Santo Agostinho

Emanuelle Ferreira Melo de Pinho - emanuellef@ fasa.edu.br

Faculdades Santo Agostinho 


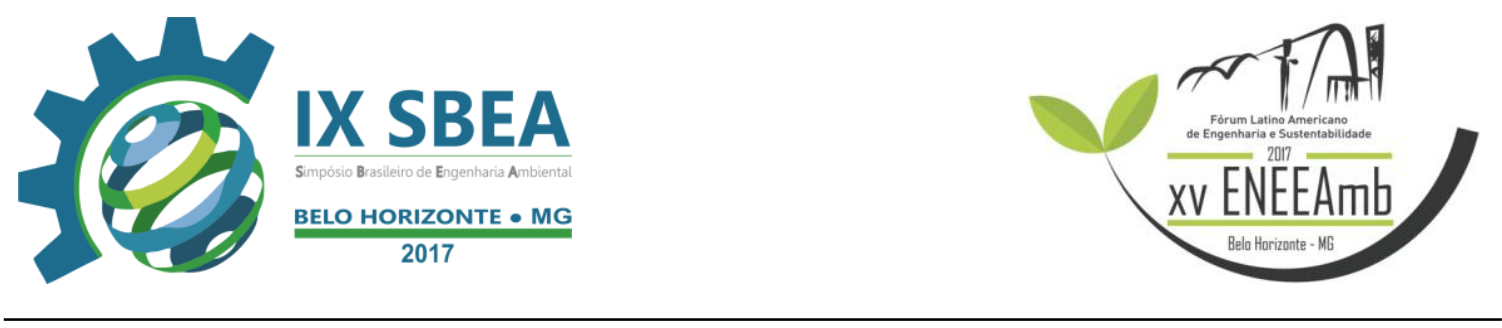

\section{RESUMO}

No Brasil o número de projetos de recuperação de áreas degradadas vem crescendo devido ao cumprimento da legislação ambiental e conscientização sobre a importância da recuperação dessas áreas. Nesse sentido, o presente trabalho teve como objetivo avaliar a germinação das sementes e o crescimento inicial de plantas de Tamboril através da utilização de diferentes métodos de quebra de dormência. Os experimentos foram realizados através da indução das sementes de Tamboril aos seguintes tratamentos: imersão em água quente a $60^{\circ}$ por 20 minutos, imersão em água em temperatura ambiente por 12 horas e escarificação mecânica com lixa de parede. Além disso, também foi utilizada uma testemunha. As sementes foram semeadas em sacolas plásticas com capacidade de 3 litros, contendo como substrato a mistura de terra, areia e esterco bovino. Esse material foi submetido a dois tipos de cultivo: à pleno sol e em viveiro coberto por sombrite com $50 \%$ de interceptação da radiação solar. O tratamento utilizando a escarificação mecânica com lixa de parede apresentou o maior índice de germinação, $100 \%$ aos 30 dias, para o cultivo sob sombreamento. As plantas que apresentaram a maior altura foram as submetidas à escarificação mecânica com lixa de parede, que atingiram um total de $24,25 \mathrm{~cm}$ aos 60 dias, para o cultivo no sol. O mesmo comportamento ocorreu para a variável diâmetro do caule, onde, os materiais em pleno sol e o cultivo sob sombreamento apresentaram 4,95 e 4,83 cm aos 60 dias, respectivamente. $\mathrm{O}$ menor diâmetro do caule foi apresentado na testemunha apenas para o cultivo em pleno sol, já que as sementes sob sombreamento não germinaram.

Palavras-chave: Superação de dormência, Germinação, Tamboril.

\section{INTRODUÇÃO/OBJETIVO}

A produção de espécies florestais é um entrave no processo de recuperação de áreas degradadas, pois, as suas sementes são de difícil germinação devido à dormência e ações inibitórias do processo germinativo natural. O conhecimento de como os fatores internos e externos influenciam na germinação e na dormência das sementes de cada espécie e os métodos utilizados para superar essa dormência permitem o controle do armazenamento, germinação das sementes e produção de mudas. 


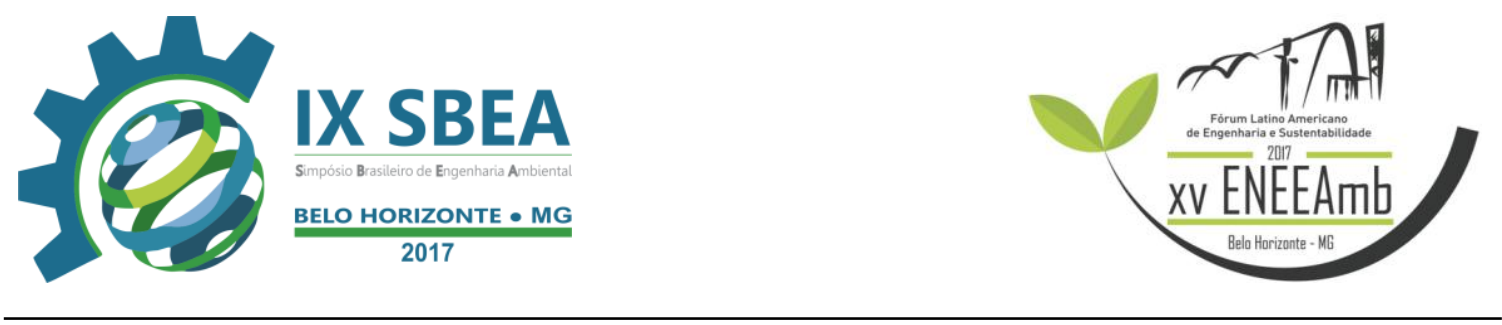

A dormência é um mecanismo natural das sementes, quando as condições para o seu desenvolvimento não é favorável, assim, elas podem sobreviver até que essas condições adequadas se restabeleçam. A produção de mudas e propagação de espécies florestais é, muitas vezes, limitada pela ocorrência de dormência, induzindo grande desuniformidade entre as mudas e maior demanda de tempo na sua produção. Torna-se importante salientar que, nas espécies florestais nativas é comum a presença de sementes que necessitam de quebra de dormência para que haja germinação, mesmo em condições ambientais aparentemente favoráveis. Diante do exposto, é necessário o desenvolvimento de pesquisas sobre as condições que proporcionam uma germinação rápida e uniforme das sementes, sendo importante para a padronização do desenvolvimento inicial das plântulas.

De acordo com Mori et al. (2012), as técnicas mais usuais para a quebra de dormência em sementes são a escarificação química, escarificação mecânica, imersão em água quente ou choque térmico, imersão em água fria, imersão em água corrente, estratificação a frio, alternância de temperatura, quebra de dormência combinada.

O Tamboril (Enterolobium contortisiliquum) é uma árvore pertencente à família Fabaceae, sendo ideal para revegetação de áreas degradadas, pela boa adaptabilidade, crescimento rápido e boa sombra. É uma espécie pioneira e muito rústica, sendo também apropriada para áreas de reflorestamento. Para a utilização do tamboril no processo de reflorestamento, faz-se necessário a reprodução da espécie, que tem como obstáculo a dureza tegumentar de suas sementes, a qual consiste na impermeabilidade a água, dificultando o processo de germinação. Neste sentido, assim, é indispensável a quebra de dormência dessas sementes acelerando o seu processo de germinação. Neste sentido, o objetivo do presente trabalho é avaliar a germinação de sementes e crescimento inicial das plântulas de Tamboril através da utilização de diferentes tipos de quebra de dormência.

\section{METODOLOGIA}

Os experimentos foram realizados na área experimental das Faculdades Santo Agostinho, Campus JK em Montes Claros, MG. Para a realização do trabalho foram 
coletadas sementes de Tamboril nos meses de maio e junho de 2016, na região de Coração de Jesus, norte de Minas Gerais.

Após a coleta, os frutos foram encaminhados ao laboratório de Engenharia Ambiental, onde as sementes foram extraídas e selecionadas as sadias e com boa conformação para realização dos testes de quebra de dormência.

As sementes foram submetidas aos seguintes tratamentos: imersão em água quente a $60^{\circ}$ por 20 minutos, imersão em água em temperatura ambiente por 12 horas e escarificação mecânica com lixa de parede. Além disso, também foi utilizada uma testemunha (sem tratamento). Após a indução dos tratamentos, as sementes foram semeadas em sacolas plásticas com capacidade de 3 litros, contendo como substrato a mistura de terra, areia e esterco bovino (Figura 1).
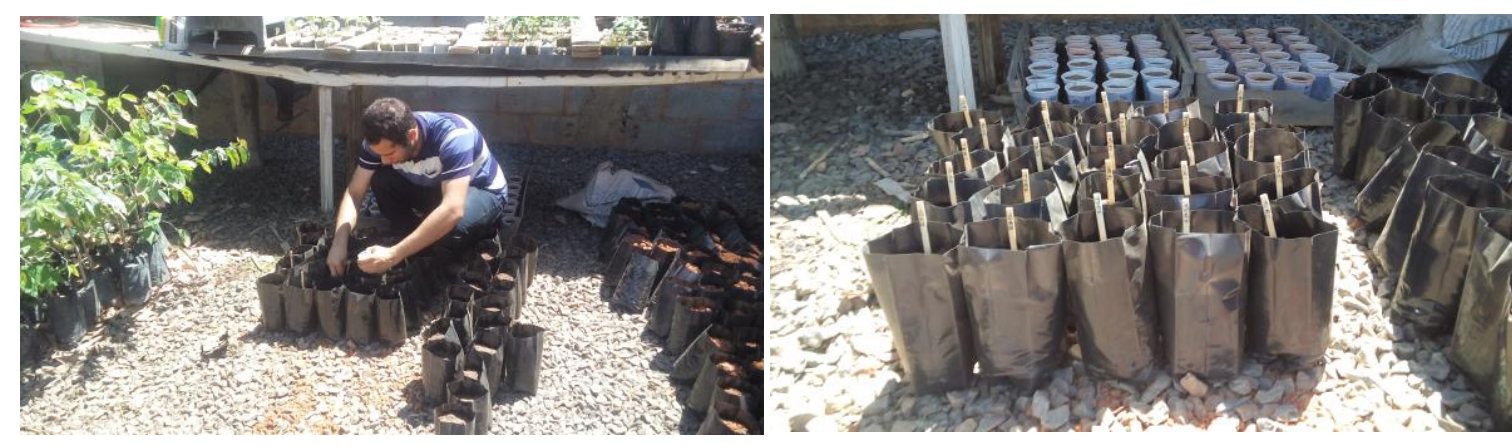

Figura 1 - Montagem e condução do experimento. Sementes de Tamboril semeadas em sacolas plásticas com capacidade de 3 litros, contendo como substrato a mistura de terra, areia e esterco bovino.

Esse material foi submetido a dois tipos de cultivo: à pleno sol e em viveiro coberto por sombrite com $50 \%$ de interceptação da radiação solar. Assim, foram totalizados 8 tratamentos, constituído de 5 repetições para cada tratamento. O material experimental foi irrigado diariamente e, aos 30 dias e 60 dias após a indução dos tratamentos, foram avaliadas a porcentagem de germinação, a altura das plantas e o diâmetro do caule.

\section{RESULTADOS E DISCUSSÃO}




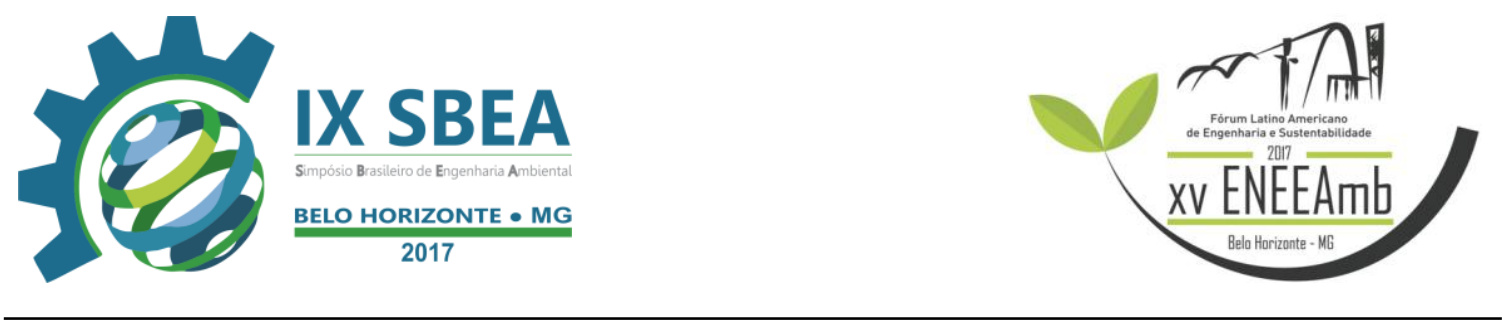

Para os testes de quebra de dormência e germinação de sementes de Tamboril foram utilizados os seguintes tratamentos: imersão em água à temperatura ambiente por 12 horas, imersão em água quente à $60^{\circ} \mathrm{C}$ por 20 minutos, escarificação mecânica com lixa de parede e uma Testemunha. A quebra de dormência através da imersão em água por 12 horas apresentou uma baixa eficiência no processo germinativo, sendo que, nesse método apenas $20 \%$ das sementes germinaram quando foram cultivadas a pleno sol, enquanto que, para as sementes que permaneceram sob sombreamento a germinação foi zero.

A temperatura da água exerce influência sobre o processo de germinação, pois, nas sementes que permaneceram em água a $60^{\circ} \mathrm{C}$ por 20 minutos a taxa de germinação foi de $40 \%$ a pleno sol e $80 \%$ para o material cultivado na sombra. Para a escarificação com lixa de parede, foi apresentado um índice de germinação elevado, para as duas situações de cultivo, sendo que, na sombra a germinação das sementes foi de $100 \%$. Quando não foi utilizado nenhum tratamento para a superação da dormência dessas sementes (Testemunha) a germinação apresentou baixa eficiência, apenas $40 \%$ aos 60 dias de avaliação (Tabela 1).

Tabela 1 - Germinação média de sementes de Tamboril em diferentes tratamentos e períodos de avaliação.

\begin{tabular}{|c|c|c|c|c|}
\hline \multirow{4}{*}{ TRATAMENTOS } & \multicolumn{4}{|c|}{ GERMINAÇÃ̃ (\%) } \\
\hline & \multicolumn{2}{|c|}{ Pleno sol } & \multicolumn{2}{|c|}{ Sombreamento } \\
\hline & \multicolumn{2}{|c|}{ Dias } & \multicolumn{2}{|c|}{ Dias } \\
\hline & 30 & 60 & 30 & 60 \\
\hline Testemunha & 20 & 40 & 0 & 0 \\
\hline $\begin{array}{l}\text { Imersão em água por } \\
12 \text { horas }\end{array}$ & 20 & 20 & 0 & 0 \\
\hline $\begin{array}{l}\text { Imersão em água } \\
\text { quente à } 60^{\circ} \mathrm{C} \text { por } 20 \\
\text { minutos }\end{array}$ & 40 & 40 & 80 & 80 \\
\hline $\begin{array}{l}\text { Escarificação com lixa } \\
\text { de parede }\end{array}$ & 60 & 60 & 100 & 100 \\
\hline
\end{tabular}

A Figura 2 apresenta as plantas de Tamboril aos 60 dias após a indução dos tratamentos para a quebra de dormência. 

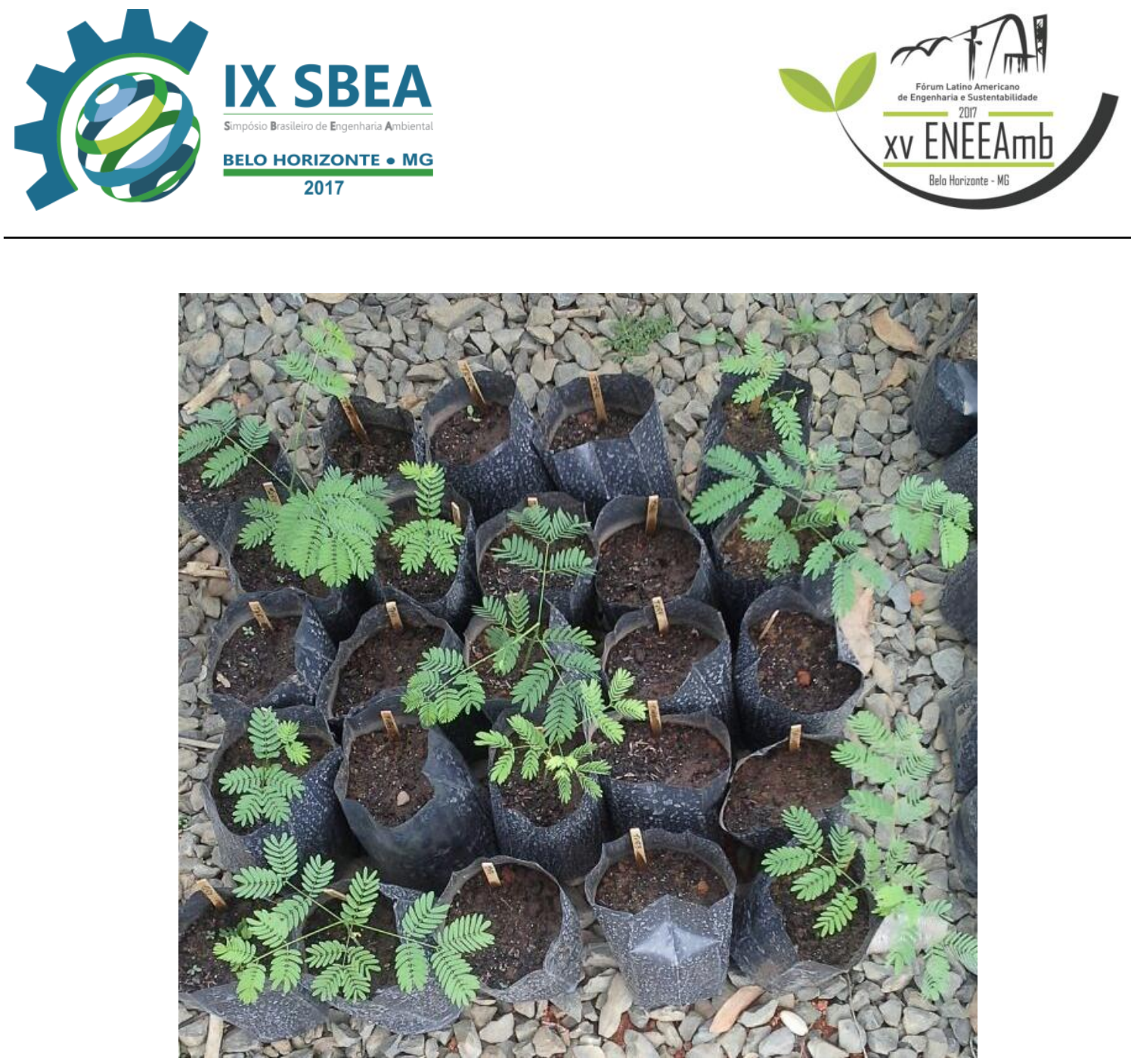

Figura 2 - Plantas de Tamboril aos 60 dias após a indução dos tratamentos para a quebra de dormência.

No presente estudo a forma mais eficiente da quebra de dormência foi através da escarificação mecânica com lixa de parede. Para Bianchetti et al. (1998) a forma mais eficiente para a superação da dormência em sementes é através do ácido sulfúrico. Esses autores concluíram que, a imersão em ácido sulfúrico, por 16 minutos, supera a dormência com $83 \%$ de germinação e que a escarificação manual somente é viável quando são utilizadas pequenas quantidades de sementes (1 kg a 10kg de sementes), tanto para o plantio direto como para a produção de mudas. À medida que a demanda do reflorestamento exige maiores quantidades de sementes (acima de 10kg), o processo de escarificação manual perde sua importância prática e outros testes, mais eficientes, devem ser aplicados para superar a dormência. O processo de quebra de dormência através do uso de lixa de parede é um método de fácil uso e de baixo custo, tornando-se uma alternativa interessante para pequenos produtores e pequenas áreas de cultivo. 


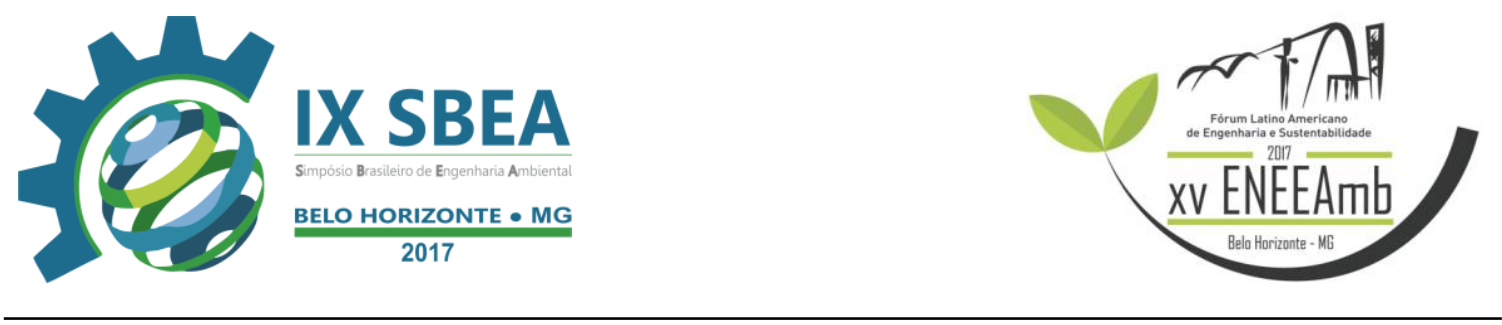

As maiores alturas das plantas produzidas foram observadas nos tratamentos de imersão em água quente e escarificação com lixa de parede, sendo a altura máxima observada de $24,25 \mathrm{~cm}$ aos 60 dias para as mudas provenientes do tratamento de escarificação com lixa. Apesar do maior índice de germinação ter ocorrido nas plantas sob sombreamento, em relação à altura, as plantas cultivadas em pleno sol apresentaram maiores valores, evidenciando assim, a importância fundamental da luz do sol para o crescimento e desenvolvimento das espécies vegetais. $\mathrm{O}$ sombreamento pode ter isso importante para a germinação por favorecer a retenção de água no substrato, impulsionando assim, o processo germinativo. As menores alturas foram observadas para as plantas cujas sementes não foram submetidas a nenhum tipo de quebra de dormência (Tabela 2).

Tabela 2 - Altura média de plantas de plantas Tamboril em diferentes tratamentos e períodos de avaliação.

\begin{tabular}{|c|c|c|c|c|}
\hline \multirow{4}{*}{ TRATAMENTOS } & \multicolumn{4}{|c|}{ ALTURA DA PLANTA (mm) } \\
\hline & \multicolumn{2}{|c|}{ Pleno sol } & \multicolumn{2}{|c|}{ Sombreamento } \\
\hline & \multicolumn{2}{|c|}{ Dias } & \multicolumn{2}{|c|}{ Dias } \\
\hline & 30 & 60 & 30 & 60 \\
\hline Testemunha & 9,00 & 15,55 & 0 & 0 \\
\hline $\begin{array}{l}\text { Imersão em água por } \\
12 \text { horas }\end{array}$ & 13,00 & 20,00 & 0 & 0 \\
\hline $\begin{array}{l}\text { Imersão em água } \\
\text { quente à } 60^{\circ} \mathrm{C} \text { por } 20 \\
\text { minutos }\end{array}$ & 10,75 & 18,50 & 10,00 & 16,2 \\
\hline $\begin{array}{l}\text { Escarificação com lixa } \\
\text { de parede }\end{array}$ & 14,00 & 24,25 & 12,00 & 18,50 \\
\hline
\end{tabular}

As plantas que apresentaram o maior diâmetro do caule foram às submetidas ao tratamento de escarificação mecânica com lixa de parede tanto a pleno sol, como no cultivo sob sombreamento, apresentando 4,95 e $4,83 \mathrm{~cm}$ aos 60 dias, respectivamente (Tabela 3). O menor diâmetro do caule foi apresentado na testemunha apenas para o cultivo em pleno sol, já que as sementes sob sombreamento não germinaram. 


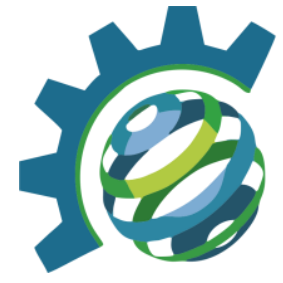

Tabela 3 - Altura média de plantas de plantas Tamboril em diferentes tratamentos e períodos de avaliação.

\begin{tabular}{|c|c|c|c|c|}
\hline \multirow{4}{*}{ TRATAMENTOS } & \multicolumn{4}{|c|}{ DIÂMETRO DO CAULE (mm) } \\
\hline & \multicolumn{2}{|c|}{ Pleno sol } & \multicolumn{2}{|c|}{ Sombreamento } \\
\hline & \multicolumn{2}{|c|}{ Dias } & \multicolumn{2}{|c|}{ Dias } \\
\hline & 30 & 60 & 30 & 60 \\
\hline Testemunha & 1,90 & 3,00 & 0 & 0 \\
\hline $\begin{array}{l}\text { Imersão em água por } \\
12 \text { horas }\end{array}$ & 2,08 & 3,48 & 0 & 0 \\
\hline $\begin{array}{l}\text { Imersão em água } \\
\text { quente à } 60^{\circ} \mathrm{C} \text { por } 20 \\
\text { minutos }\end{array}$ & 2,34 & 3,75 & 2,04 & 2,87 \\
\hline $\begin{array}{l}\text { Escarificação com lixa } \\
\text { de parede }\end{array}$ & 2,44 & 4,95 & 2,45 & 4,83 \\
\hline
\end{tabular}

A Figura 3 apresenta uma planta de Tamboril aos 60 dias para avaliação do diâmetro do caule.

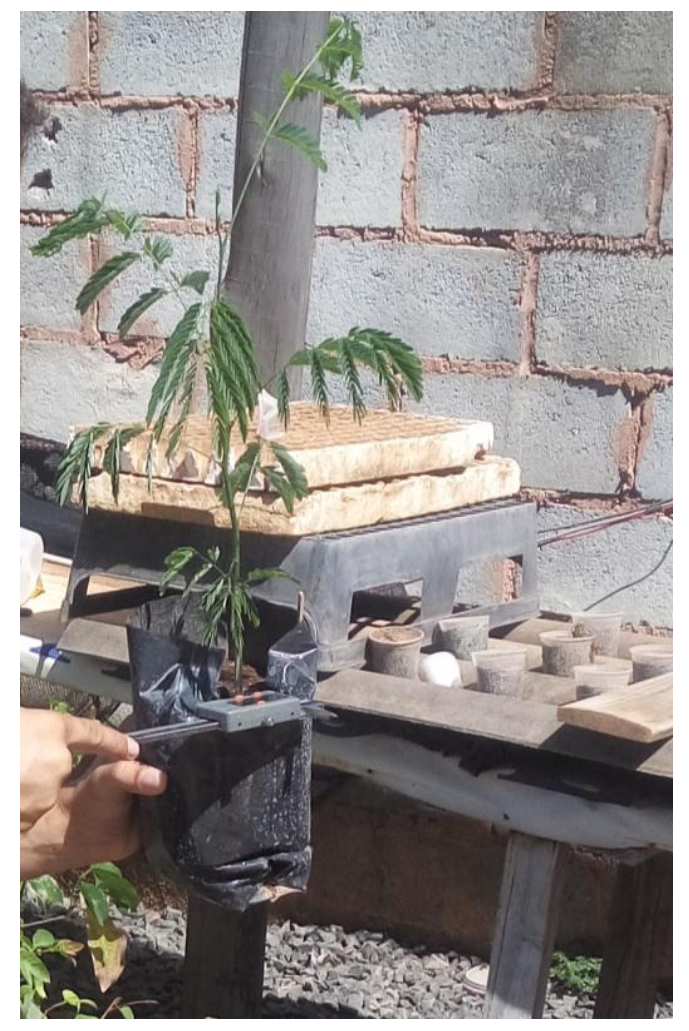

Figura 3 - Planta de Tamboril aos 60 dias após a indução dos tratamentos sendo avaliado o diâmetro do caule. 


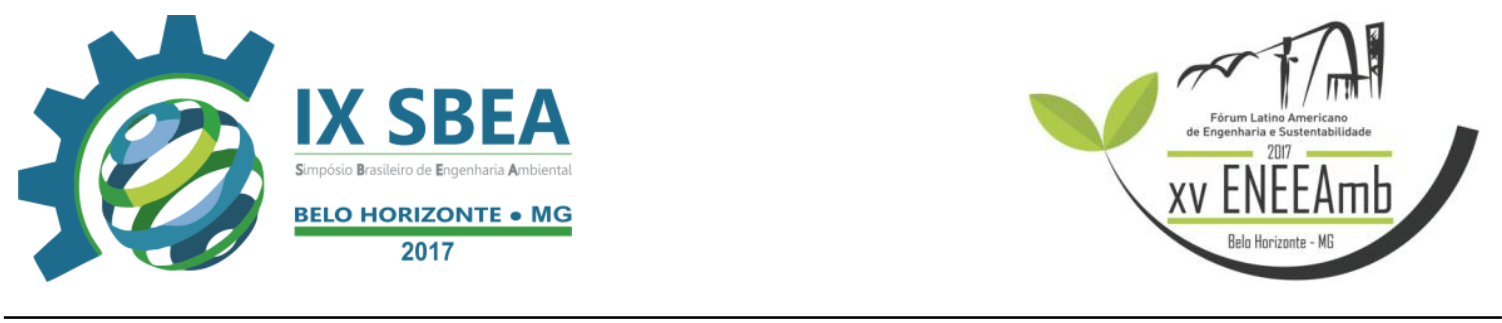

A escarificação mecânica é uma metodologia utilizada para a quebra de dormência, onde ocorre o rompimento ou abrasão da película que envolve a semente, aumentando desta forma a permeabilidade a água que consequentemente estimular a germinação. Alexandre et al., (2009) ao estudar o efeito de agentes físicos e químicos na superação de dormência em sementes de Tamboril obtiveram melhores resultados de emergência em sementes que sofreram escarificação em liquidificador doméstico (80\%), o qual não diferiu estatisticamente dos tratamentos com ácido sulfúrico por 10 minutos (58\%), escarificação com lixa (75\%), escarificação com lixa mais 12 horas de embebição em água (68\%), trincagem das sementes em torno mecânico (69\%).

As mudas produzidas no presente trabalho permanecerão por mais um tempo na área experimental das Faculdades Santo Agostinho até atingirem maior porte para então serem doadas à população ou mesmo serem utilizadas para a recuperação de áreas degradadas.

Os testes de quebra de dormência permitiram concluir que é possível a produção de mudar de qualidade e em quantidades elevadas, mesmo que as sementes possuam o tegumento duro, dificultando a infiltração da água, embebição e germinação. Os diferentes testes possibilitam a acelaração no processo de germinação, facilitando assim, a produção de mudas em larga escala, tão necessárias para os projetos de recuperação de áreas degradadas.

\section{CONCLUSÕES/RECOMENDAÇÕES}

O tratamento utilizando a escarificação mecânica com lixa de parede apresentou o maior índice de germinação, $100 \%$ aos 30 dias, para o cultivo sob sombreamento.

As plantas que apresentaram a maior altura foram as submetidas à escarificação mecânica com lixa de parede, que atingiram um total de $24,25 \mathrm{~cm}$ aos 60 dias, para o cultivo no sol. O mesmo comportamento ocorreu para a variável diâmetro do caule, onde, os materiais em pleno sol e o cultivo sob sombreamento apresentaram 4,95 e 4,83 $\mathrm{cm}$ aos 60 dias, respectivamente. O menor diâmetro do caule foi apresentado na testemunha apenas para o cultivo em pleno sol, já que as sementes sob sombreamento não germinaram. 


\section{REFERÊNCIAS BIBLIOGRÁFICAS}

ALEXANDRE, R. S.; GONÇALVES, F. G.; ROCHA, A. P.; ARRUDA, M. P.; LEMES, E. Q. Tratamentos físicos e químicos na superação de dormência em sementes de Enterolobium contortiliquum (Vell.) Morong. Revista Brasileira de Ciências Agrárias, Recife-PE, v. 4, n. 2, p. 156-159, 2009.

BIANCHETTI, A.; RAMOS, A. Comparação de tratamentos para superar a dormência de sementes de Canafístula peltophorum dubium (Spreng.) Taubert. Boletim de Pesquisa Florestal, n. 4, p. 91-99, 1982.

MORI, E. S.; PIÑA-RODRIGUES, F. C. M.; FREITAS, N. P.; MARTINS, R. B. Sementes florestais: guia para germinação de 100 espécies nativas. São Paulo: Instituto Refloresta, 2012. 159 p. 